Case Report

\title{
Combined Hepatocholangiocarcinoma Associated with Humoral Hypercalcemia of Malignancy and Chronic Inflammatory Demyelinating Polyneuropathy
}

\author{
Ruben Manuel Luciano Colunga Biancatelli, ${ }^{1}$ Marco Ciacciarelli ${ }_{(D)}{ }^{1}$ Alessandro Polidoro, ${ }^{1}$ \\ Piera Clemenzi, ${ }^{1}$ Viviana Congedo, ${ }^{1}$ Leonardo Calvosa, ${ }^{1}$ Eleonora D'Armiento, ${ }^{1}$ \\ Carmen Misurale, ${ }^{1}$ Davide Bellini, ${ }^{2}$ Stefano Badia, ${ }^{2}$ Massimiliano Mancini, ${ }^{3}$ \\ Vincenzo Petrozza, ${ }^{3}$ and Luigi Iuliano $\mathbb{D i D}^{1}$ \\ ${ }^{1}$ Department of Medico-Surgical Sciences and Biotechnologies, Internal Medicine Unit, ICOT Hospital, "Sapienza” University \\ of Rome, Via Franco Faggiana 34, 04100 Latina, Italy \\ ${ }^{2}$ Department of Radiological Sciences, Oncology and Pathology, ICOT Hospital, "Sapienza” University of Rome, Via Franco \\ Faggiana 34, 04100 Latina, Italy \\ ${ }^{3}$ Department of Medico-Surgical Sciences and Biotechnologies, Pathology Unit, ICOT Hospital, "Sapienza" University of Rome, \\ Via Franco Faggiana 34, 04100 Latina, Italy
}

Correspondence should be addressed to Marco Ciacciarelli; marco.ciacciarelli@uniroma1.it

Received 17 December 2018; Accepted 17 June 2019; Published 24 June 2019

Academic Editor: Jose I. Mayordomo

Copyright (C) 2019 Ruben Manuel Luciano Colunga Biancatelli et al. This is an open access article distributed under the Creative Commons Attribution License, which permits unrestricted use, distribution, and reproduction in any medium, provided the original work is properly cited.

Paraneoplastic syndromes are often a diagnostic challenge to doctors and may have a heterogeneous presentation, including humoral hypercalcemia of malignancy (HHM), most commonly caused by squamous cell cancer and renal, ovarian, endometrial, and breast cancer. Chronic inflammatory demyelinating polyneuropathy (CIDP) has been described in patients affected by several types of cancer, especially hematologic malignancies, and a possible paraneoplastic pathogenesis of this neurological disease has been suggested. This report describes a 56-year-old man with a history of CIDP diagnosed 3 months earlier and persistently elevated aminotransferases for 18 months who was admitted to our internal medicine unit with abdominal pain, fatigue, and severe hypercalcemia with low serum intact parathyroid hormone. Parathyroid hormone-related protein (PTH-rP) was markedly high. Liver imaging showed a large hepatic mass in the right lobe, and percutaneous ultrasound-guided biopsy revealed histopathological findings consistent with a combined hepatocholangiocarcinoma (CHCC). We supposed that both HHM and CIDP could represent a paraneoplastic manifestation of CHCC.

\section{Introduction}

Paraneoplastic syndromes are often a diagnostic challenge to doctors and may present as any of a wide variety of clinical syndromes resulting from the release of self-peptides or self-like peptides to the production of autoimmune antibodies. Humoral hypercalcemia of malignancy (HHM), hypercalcemia caused by systemic secretion of parathyroid hormone-related protein (PTH-rP) by malignant cells, is considered a paraneoplastic syndrome, and it is most commonly caused by squamous cell cancer (e.g., of the head and neck, esophagus, cervix, and lung) and renal, ovarian, endometrial, and breast cancer [1]. Paraneoplastic neurological syndromes (PNS) may have a heterogeneous presentation, including polyneuropathies, and can occur with any type of cancer, especially small cell lung cancer, ovarian and breast cancer, neuroendocrine tumors, thymoma, and lymphoma. Interestingly, PNS more commonly develop prior 


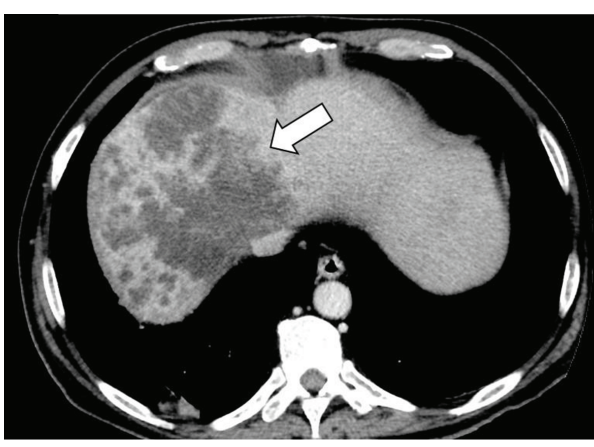

(a)

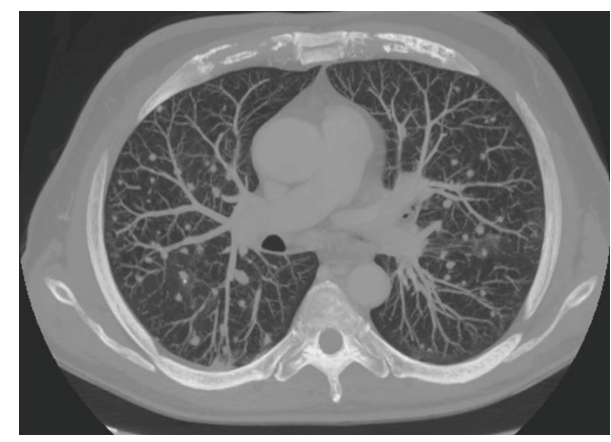

(b)

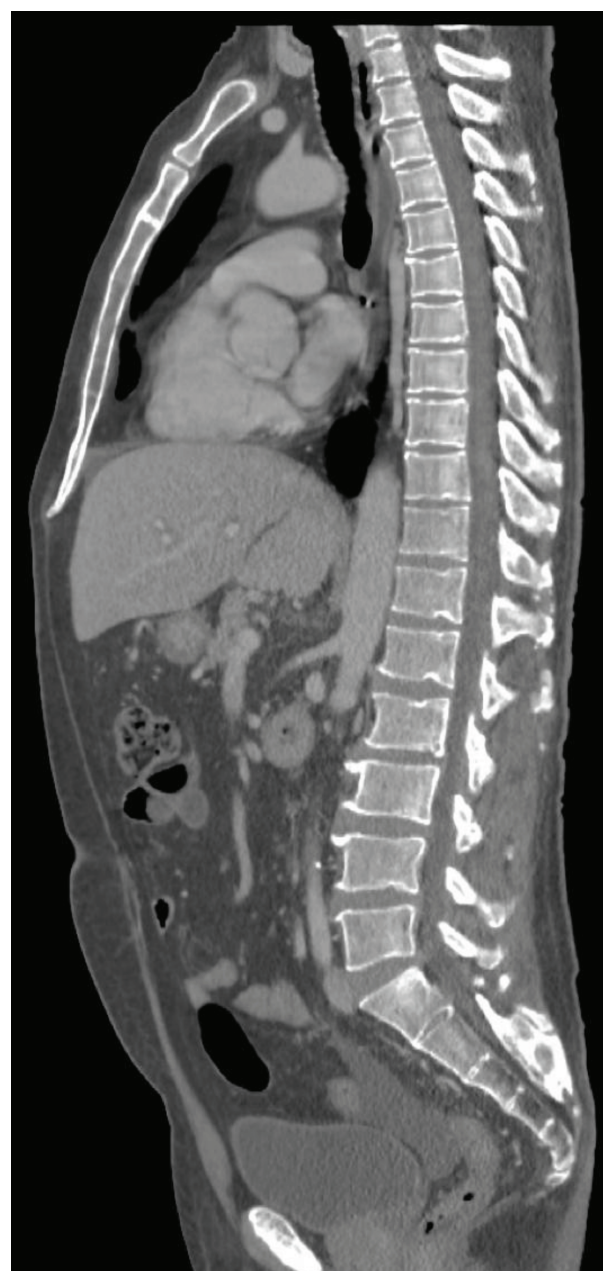

(c)

Figure 1: (a) Portal phase CT scan shows large, hypoattenuating mass (arrows) in the right hepatic lobe, consistent with mass-forming peripheral cholangiocarcinoma (arrow). (b) Maximum intensity projection reconstruction of axial CT scan of the chest demonstrates multiple bilateral lung nodules consistent with metastasis. (c) Sagittal CT reconstruction of the spine showed no bony lesions.

to the cancer diagnosis and are frequently associated with antineuronal antibodies that can be measured in serum and cerebrospinal fluid [2]. Chronic inflammatory demyelinating polyneuropathy (CIDP) is an autoimmune peripheral neuropathy frequently described in association with several types of cancer, especially hematologic malignancies. We present the first case of combined hepatocholangiocarcinoma (CHCC) presenting with HHM in a patient with a CIDP.

\section{Case}

A 56-year-old man was referred to our internal medicine unit with abdominal pain, fatigue, and persistently elevated aminotransferases for 18 months. Three months earlier, he had been evaluated for numbness and weakness starting over the distal aspects of his four limbs and slowly progressing proximally over the last three years. Neurological 


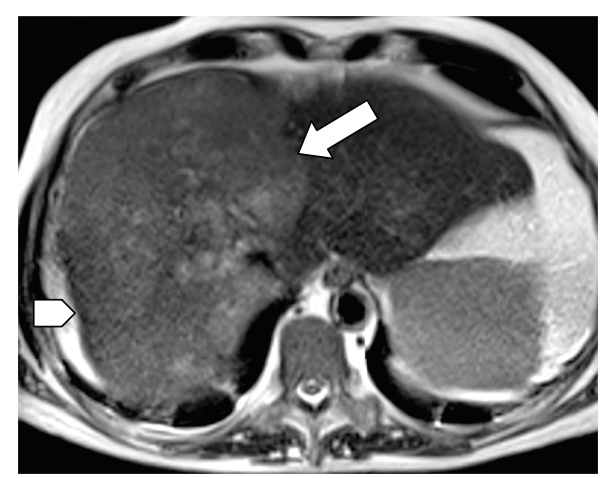

(a)

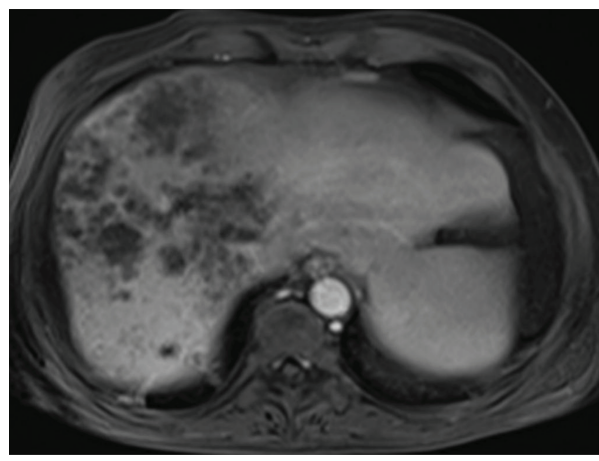

(c)

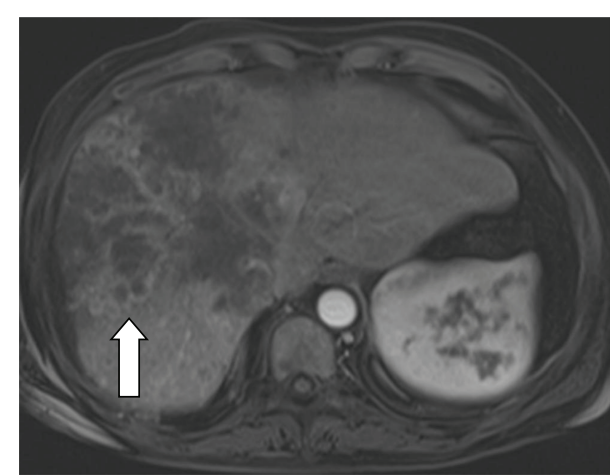

(b)

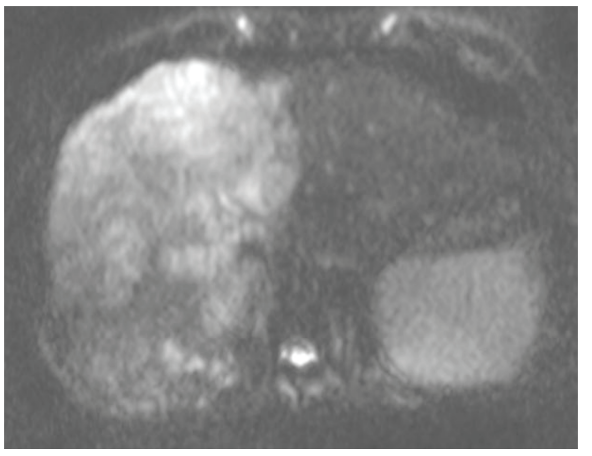

(d)

FIGURE 2: (a) Axial T2-weighted magnetic resonance (MR) image shows a hyperintense mass located in the right hepatic lobe (arrow). There is mild parenchymal atrophy with minimal capsular retraction peripheral to the posterior aspect of the lesion (arrowhead). T1-weighted MR images show irregular, ragged rim enhancement (arrow in (b)) with gradual centripetal enhancement in the portal phase (c). (d) Diffusion weighted image demonstrates high cellularity.

examination performed at that time revealed walking difficulties and moderate muscle weakness in both lower and upper limbs $(F=3.5-4)$, generalized tendon areflexia, and mild sensory loss with stock and glove distribution. Electromyography/electroneurography (EMG/ENG) showed diffusely reduced motor and sensory nerve conduction velocity (mean motor nerve conduction velocity $22 \mathrm{~m} / \mathrm{s}$ ), with a dishomogeneous pattern, and absent $F$ waves. Isolated hyperproteinorrachia $(1.15 \mathrm{~g} / \mathrm{L})$ was found on cerebrospinal fluid (CSF) examination. The clinical, EMG/ENG, and CSF results were consistent with a diagnosis of CIDP, which was subsequently successfully treated with IV immunoglobulins.

On admission, the patient's temperature was $36^{\circ} \mathrm{C}$, heart rate 125 beats per minute, blood pressure $110 / 80 \mathrm{mmHg}$, and oxygen saturation $94 \%$ while he was breathing ambient air. On physical examination, peripheral edema, bibasal pulmonary rales, hepatomegaly, and severe sensory and motor deficits located to the upper and lower limbs were noted. Laboratory data on admission showed the following values: aspartate aminotransferase (AST) $166 \mathrm{IU} / \mathrm{L}$ (normal range 17-59 IU/L), alanine aminotransferase (ALT) $64 \mathrm{IU} / \mathrm{L}$ (normal range 21-72 IU/L), gamma glutamyl-transferase $358 \mathrm{IU} / \mathrm{L}$ (normal range 15-73 IU/L), alkaline phosphatase $173 \mathrm{IU} / \mathrm{L}$ (normal range $38-126 \mathrm{IU} / \mathrm{L}$ ), total bilirubin $1.28 \mathrm{mg} / \mathrm{dL}$ (normal range $0.20-1.30 \mathrm{mg} / \mathrm{dL}$ ), albumin $2.8 \mathrm{~g} / \mathrm{dL}$ (normal range 3.6-5.5 g/dL), lactate dehydrogenase $993 \mathrm{IU} / \mathrm{L}$ (normal range 313-618 IU/L), total serum calcium level $14.1 \mathrm{mg} / \mathrm{dL}$ (normal range $8.8-10.2 \mathrm{mg} / \mathrm{dL}$ ), phosphorous $2.8 \mathrm{mg} / \mathrm{dL}$ (normal range $2.9-4.8 \mathrm{mg} / \mathrm{dL}$ ), C-reactive protein $14.6 \mathrm{mg} / \mathrm{dL}$ (normal range $<1.0 \mathrm{mg} / \mathrm{dL}$ ), and ferritin $1669 \mathrm{ng} / \mathrm{mL}$ (normal range $20-325 \mathrm{ng} / \mathrm{mL}$ ). Viral markers for hepatitis $B$ and $\mathrm{C}$ were negative. Serum intact PTH was low $(4 \mathrm{pg} / \mathrm{mL})$ (normal range $20-104 \mathrm{pg} / \mathrm{mL}$ ). Moreover, anti-ganglioside antibodies (GD1bIgG and GM1IgG) were found in serum. Given the predominantly infiltrative pattern of altered liver function tests and the severe hypercalcemia with low serum intact PTH, imaging studies and further blood tests were performed to rule out cancer or metastases.

Whole body multidetector computed tomography (MDCT) scan showed a large hypoattenuating hepatic mass in the right lobe (maximum axial dimension $13 \mathrm{~cm}$ ) characterized by heterogeneous peripheral enhancement, associated with secondary lesions located in the spleen and lung (more than 30 nodules); no evidence of bone metastasis was found (Figure 1). The following magnetic resonance imaging, performed to confirm the diagnostic hypothesis from the previous CT study, showed typical findings of peripheral CHCC (Figure 2). Alpha-phetoprotein was $247.8 \mathrm{ng} / \mathrm{mL}$ (normalvalue $<9 \mathrm{ng} / \mathrm{mL}$ ), gastrointestinal cancer antigen (GICA) was $132 \mathrm{U} / \mathrm{mL}$ (normal value $<37 \mathrm{U} / \mathrm{mL}$ ), and carcinoembryonic antigen (CEA) was $9.14 \mathrm{ng} / \mathrm{mL}$ (normal range $0-5 \mathrm{ng} / \mathrm{mL})$. PTH-rP was markedly high $(147 \mathrm{ng} / \mathrm{mL}$; normal range $8.5-20.0 \mathrm{ng} / \mathrm{mL}$ ). 


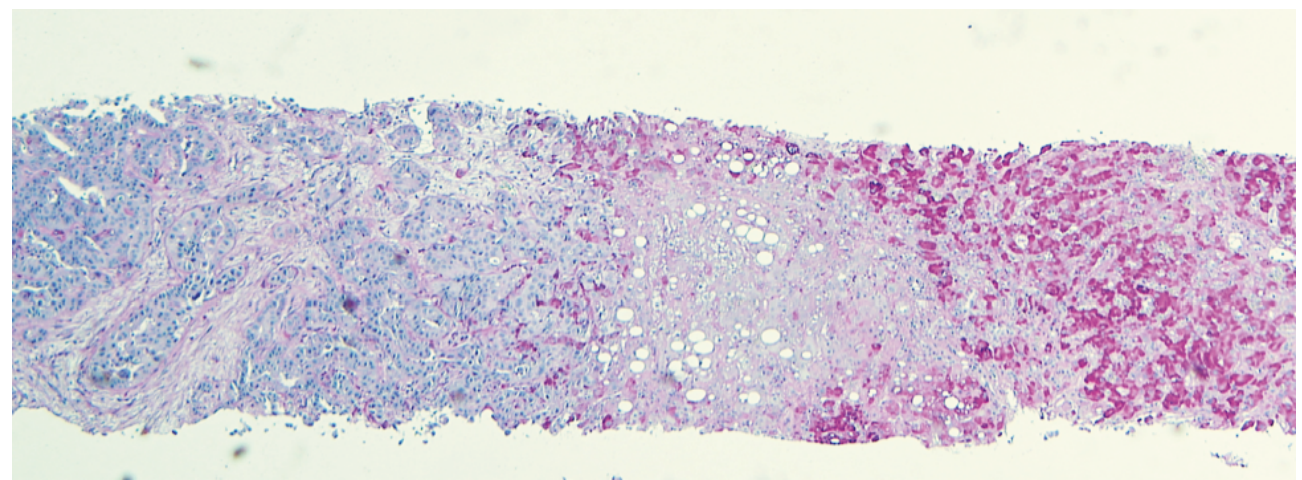

(a)

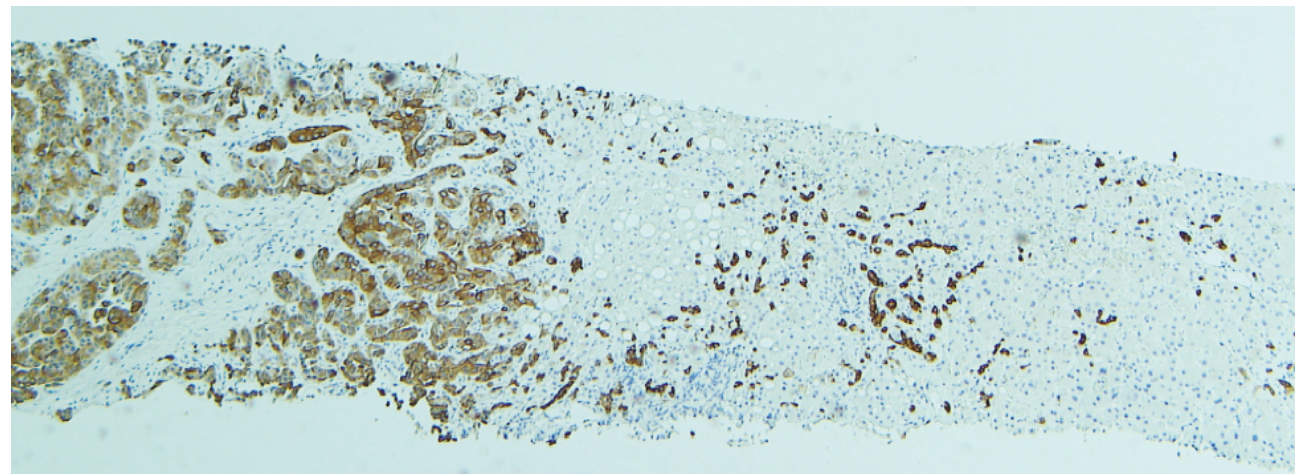

(b)

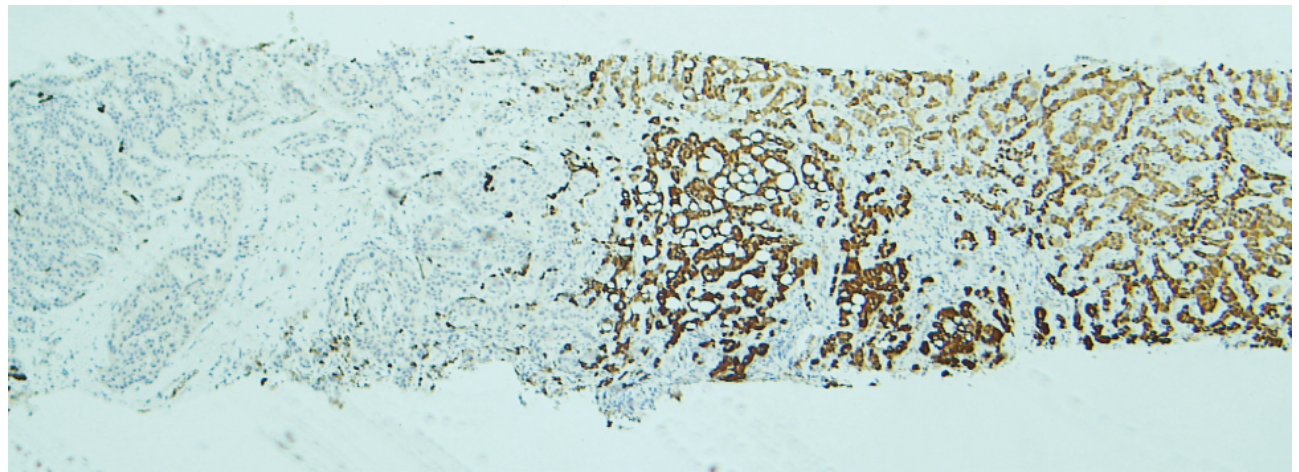

(c)

FIgURE 3: (a) Needle biopsy of the neoplasia showing t solid nests of hepatocarcinoma on the right side with strong cytoplasmic PAS stain and cholangiocarcinoma on the left, with ill formed glands (PAS stain, 1.4x original magnification). (b) Immunoperoxidase staining showed strong CK7 expression on the glandular neoplasia (left side) and negative stain on the hepatocellular carcinoma (right side). (c) Hep-Par1 staining showed a counter-opposite staining pattern (immunoperoxidase stains B and C, 1.4x original magnification).

Percutaneous ultrasound-guided biopsy of the hepatic tumor showed a mixed epithelial neoplasia comprising: (1) trabeculae and solid nests composed of large cells with pleomorphic nuclei and granular cytoplasm intermingled with (2) branching pseudoglandular structures composed of cuboidal/columnar cells with atypical nuclei. Nests and trabeculae showed strong immunohistochemical staining for cytokeratin 8/18 and HepPar1 while pseudoglandular structures stained selectively for cytokeratin 7 and cytokeratin 19 (Figure 3). A diagnosis of "Stage IV CHCC associated to HHM and CIDP" was made.

The general status of patient rapidly worsened, and he became bedridden soon thereafter. After discussion with the patient about the prognosis of his disease, he declined further treatments and arrangements for hospice care were made prior to discharge.

\section{Discussion}

Hypercalcemia of malignancy is typically found in patients with advanced stage cancers and is one of the most lifethreatening metabolic disorders. It may result from a marked increase in osteoclastic bone resorption or release of PTH, PTH-rP, or 1,25-dihydroxyvitamin D by the tumor. Acting through a common PTH/PTH-rP receptor, PTH-rP inhibits calcium excretion from the kidney and promotes bone 
resorption leading to hypercalcemia [3]. As shown in studies investigating the prevalence and prognosis of different paraneoplastic syndromes in HCC, HHM can be found in 4-8\% of HCC [4]. HHM has rarely been reported in patients with cholangiocarcinoma (CC) and represents a marker of poor prognosis of the disease [5-9]. CHCC is a rare tumor with poor prognosis, with incidence ranging from $1.0 \%$ to $4.7 \%$ of all primary hepatic tumors [10].

To the best of our knowledge, this is the third case of CHCC associated with HHM [11, 12] and the first one in a patient with recent diagnosis of CIDP. Involvement of the peripheral nervous system is common in patients with cancer, and any part can be affected [13]. The most frequently reported malignancies associated with CIDP are hematologic (Hodgkin's and non-Hodgkin's lymphomas, Waldenström's macroglobulinemia, chronic myelomonocytic leukemia, hairy cell leukemia, and multiple myeloma). However, CIDP has been described in patients affected by gastrointestinal malignancies (pancreatic, rectosigmoidal, esophageal, and gastric), renal cell carcinoma, lung cancer, seminoma, Kaposi's sarcoma, orbital neurogenic tumor, breast carcinoma, and melanomas, and a possible paraneoplastic pathogenesis of this neurological disease has been suggested [14-33].

It is challenging to determine whether the association of cancer and CIDP is a coincidence or could be explained by a paraneoplastic process. In our patient, CHCC diagnosis was made 3 years after the onset of neurological symptoms and 3 months after the CIDP diagnosis. Since many reported cases identified CIDP prior to the diagnosis of cancer, we supposed that CIDP could represent a paraneoplastic manifestation of CHCC. Although no association between CIDP and $\mathrm{CHCC}$ has been previously described, few cases of CIDP associated with HCC [34-36] have been described. Interestingly, one case of CIDP associated with CC has been reported [20], and in that case, cancer was diagnosed about 8 months after the onset of neurological symptoms and 5 months after the CIDP diagnosis.

In conclusion, we report the first case of CHCC associated with HHM and CIDP. Given our case and the other ones reported in the literature, primary hepatic tumors such as HCC, CC, and CHCC should always be included in the differential diagnosis of hypercalcemia of malignancy. Furthermore, in patients with CIDP and elevated aminotransferases, we suggest ordering a full panel of liver function tests, including ALP, yGT, and total bilirubin, looking for a primary hepatic tumor and considering that CIDP associated with primary biliary cirrhosis has been described as well [37]. On the other hand, we suggest that CIDP should be ruled out in patients known to have a primary hepatic tumor presenting with a compatible clinical picture suggesting a demyelinating polyneuropathy.

\section{Conflicts of Interest}

The authors declare no potential competing interests with respect to the research, authorship, and/or publication of this paper.

\section{References}

[1] A. F. Stewart, "Hypercalcemia associated with cancer," The New England Journal of Medicine, vol. 352, no. 4, pp. 373-379, 2005.

[2] R. Höftberger, M. R. Rosenfeld, and J. Dalmau, "Update on neurological paraneoplastic syndromes," Current Opinion in Oncology, vol. 27, no. 6, pp. 489-495, 2015.

[3] A. E. Mirrakhimov, "Hypercalcemia of malignancy: an update on pathogenesis and management," North American Journal of Medical Sciences, vol. 7, no. 11, pp. 483-493, 2015.

[4] N. B. Newman, S. K. Jabbour, J. D. C. Hon et al., "Hepatocellular carcinoma without cirrhosis presenting with hypercalcemia: case report and literature review," Journal of Clinical and Experimental Hepatology, vol. 5, no. 2, pp. 163-166, 2015.

[5] K. Takeda, R. Kimura, N. Nishigaki et al., "Humoral hypercalcemia of malignancy with a parathyroid hormone-related peptide-secreting intrahepatic cholangiocarcinoma accompanied by a gastric cancer," Case Reports in Endocrinology, vol. 2017, Article ID 7012520, 6 pages, 2017.

[6] N. Ashihara, K. Nakajima, Y. Nakamura et al., "Denosumab is effective for controlling serum calcium levels in patients with humoral hypercalcemia of malignancy syndrome: a case report on parathyroid hormone-related protein-producing cholangiocarcinoma," Internal Medicine, vol. 55, no. 23, pp. 34533457, 2016.

[7] S. Lim, J. Han, K. H. Park et al., "Two cases of humoral hypercalcemia of malignancy in metastatic cholangiocarcinoma," Cancer Research and Treatment, vol. 45, no. 2, pp. 145-149, 2013.

[8] Y. Yen, P. G. Chu, and W. Feng, "Paraneoplastic syndromes in cancer: case 3. Parathyroid hormone-related hypercalcemia in cholangiocarcinoma," Journal of Clinical Oncology, vol. 22, no. 11, pp. 2244-2245, 2004.

[9] J. M. Davis, R. Sadasivan, T. Dwyer, and P. Van Veldhuizen, "Case report: cholangiocarcinoma and hypercalcemia," The American Journal of the Medical Sciences, vol. 307, no. 5, pp. 350-352, 1994.

[10] S. Gera, M. Ettel, G. Acosta-Gonzalez, and R. Xu, "Clinical features, histology, and histogenesis of combined hepatocellularcholangiocarcinoma," World Journal of Hepatology, vol. 9, no. 6, pp. 300-309, 2017.

[11] M. Matsumoto, S. Wakiyama, H. Shiba et al., "Combined hepatocellular-cholangiocarcinoma producing parathyroid hormone-related protein: report of a case," Surgery Today, vol. 44, no. 8, pp. 1577-1583, 2014.

[12] A. Maarouf, M. Adham, J. Y. Scoazec, and C. Partensky, "Mixed hepato/cholangiocarcinoma with paraneoplastic hypercalcemia," Journal of Hepato-Biliary-Pancreatic Surgery, vol. 15, no. 2, pp. 224-227, 2008.

[13] J. C. Antoine and J. P. Camdessanché, "Peripheral nervous system involvement in patients with cancer," Lancet Neurology, vol. 6, no. 1, pp. 75-86, 2007.

[14] H. Koike, H. Yoshida, T. Ito et al., "Demyelinating neuropathy and autoimmune hemolytic anemia in a patient with pancreatic cancer," Internal Medicine, vol. 52, no. 15, pp. 17371740, 2013.

[15] C. Briani, R. Vitaliani, W. Grisold et al., "Spectrum of paraneoplastic disease associated with lymphoma," Neurology, vol. 76, no. 8, pp. 705-710, 2011. 
[16] J. J. Griggs, C. S. Commichau, A. P. Rapoport, and R. C. Griggs, "Chronic inflammatory demyelinating polyneuropathy in non-Hodgkin's lymphoma," American Journal of Hematology, vol. 54, no. 4, pp. 332-334, 1997.

[17] J. Cassereau, F. Letournel, S. François, F. Dubas, and G. Nicolas, "Chronic inflammatory demyelinating polyneuropathy in Waldenström's macroglobulinemia," Revue Neurologique, vol. 167, no. 4, pp. 343-347, 2011.

[18] A. Isoda, A. Sakurai, Y. Ogawa et al., "Chronic inflammatory demyelinating polyneuropathy accompanied by chronic myelomonocytic leukemia: possible pathogenesis of autoimmunity in myelodysplastic syndrome," International Journal of Hematology, vol. 90, no. 2, pp. 239-242, 2009.

[19] A. A. Fasanya, M. F. Loncharich, V. Gandhi, S. Rana, and M. Balaan, "Multiple myeloma associated chronic inflammatory demyelinating polyradiculoneuropathy: the importance of continued surveillance," Cureus, vol. 8, no. 11, 2016.

[20] J. C. Antoine, J. F. Mosnier, J. Lapras et al., "Chronic inflammatory demyelinating polyneuropathy associated with carcinoma," Journal of Neurology, Neurosurgery, and Psychiatry, vol. 60, no. 2, pp. 188-190, 1996.

[21] S. Mostoufizadeh, M. Souri, and J. de Seze, "A case of paraneoplastic demyelinating motor polyneuropathy," Case Reports in Neurology, vol. 4, no. 1, pp. 71-76, 2012.

[22] J. P. S. Chawla and A. M. Fisher, "Gastric carcinoma presenting with chronic inflammatory demyelinating polyneuropathy," The Internet Journal of Neurology, vol. 7, no. 2, pp. 1-5, 2007.

[23] K. Nishioka, M. Fujimaki, K. Kanai et al., "Demyelinating peripheral neuropathy due to renal cell carcinoma," Internal Medicine, vol. 56, no. 1, pp. 101-104, 2017.

[24] M. S. Sternbach, S. Fawcett, M. Wolsley, and R. Giammarco, "Plasma exchange in chronic inflammatory demyelinating polyneuropathies," Transfusion Science, vol. 17, no. 3, pp. 415-422, 1996.

[25] B. N. Greenspan and K. J. Felice, "Chronic inflammatory demyelinating polyneuropathy (CIDP) associated with seminoma," European Neurology, vol. 39, no. 1, pp. 57-58, 1998.

[26] Y. Celik, N. Turgut, B. Turgut, G. E. Pamuk, and M. Demir, "Chronic idiopathic demyelinating polyneuropathy (CIDP) associated with Kaposi's sarcoma," Journal of Neuro-Oncology, vol. 79, no. 3, pp. 323-324, 2006.

[27] B. L. Man and Y. P. Fu, "Neurogenic tumour of the orbit in a patient with idiopathic chronic inflammatory demyelinating polyneuropathy," BML Case Reports, vol. 2014, article bcr2014205349, 2014.

[28] Y. A. Rajabally, B. Qaddoura, and R. J. Abbott, "Steroidresponsive paraneoplastic demyelinating neuropathy and myelopathy associated with breast carcinoma," Journal of Clinical Neuromuscular Disease, vol. 10, no. 2, pp. 65-69, 2008.

[29] A. M. T. Chau, A. Yu, and M. R. Keezer, "Chronic inflammatory demyelinating polyneuropathy and metastatic melanoma," Canadian Journal of Neurological Sciences, vol. 40, no. 5, pp. 750-752, 2013.

[30] M. B. Dbouk, S. Nafissi, and A. Ghorbani, "Chronic inflammatory demyelinating polyneuropathy following malignant melanoma," Neurosciences, vol. 17, no. 2, pp. 167-170, 2012.

[31] J. A. Palma and S. Martín-Algarra, "Chronic inflammatory demyelinating polyneuropathy associated with metastatic malignant melanoma of unknown primary origin," Journal of Neuro-Oncology, vol. 94, no. 2, pp. 279-281, 2009.
[32] S. J. Bird, M. J. Brown, M. E. Shy, and S. S. Scherer, "Chronic inflammatory demyelinating polyneuropathy associated with malignant melanoma," Neurology, vol. 46, no. 3, pp. $822-$ 824, 1996

[33] D. A. Anthoney, I. Bone, and T. R. J. Evans, "Inflammatory demyelinating polyneuropathy: a complication of immunotherapy in malignant melanoma," Annals of Oncology, vol. 11, no. 9, pp. 1197-1200, 2000.

[34] M. R. Arguedas and B. M. McGuire, "Hepatocellular carcinoma presenting with chronic inflammatory demyelinating polyradiculoneuropathy," Digestive Diseases and Sciences, vol. 45, no. 12, pp. 2369-2373, 2000.

[35] K. Abe and F. Sugai, "Chronic inflammatory demyelinating polyneuropathy accompanied by carcinoma," Journal of Neurology, Neurosurgery \& Psychiatry, vol. 65, no. 3, pp. 403a404a, 1998.

[36] F. Sugai, K. Abe, T. Fujimoto et al., "Chronic inflammatory demyelinating polyneuropathy accompanied by hepatocellular carcinoma," Internal Medicine, vol. 36, no. 1, pp. 53-55, 1997.

[37] K. Y. Murata, H. Ishiguchi, R. Ando, H. Miwa, and T. Kondo, "Chronic inflammatory demyelinating polyneuropathy associated with primary biliary cirrhosis," Journal of Clinical Neuroscience, vol. 20, no. 12, pp. 1799-1801, 2013. 


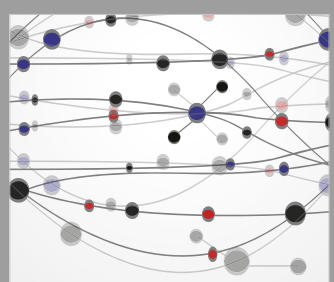

The Scientific World Journal
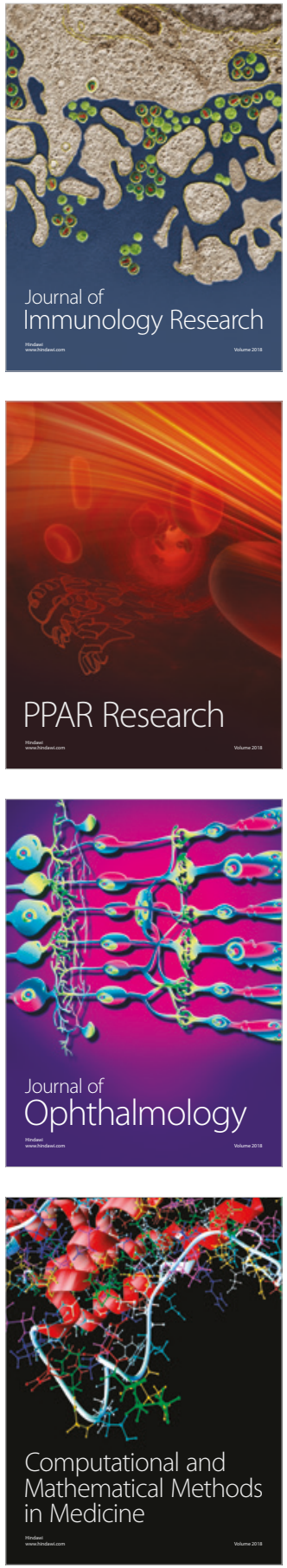

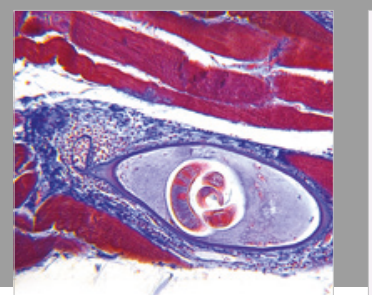

Gastroenterology Research and Practice

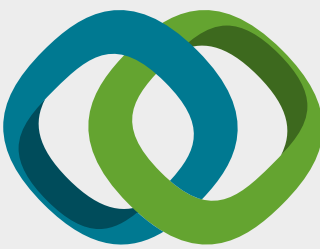

\section{Hindawi}

Submit your manuscripts at

www.hindawi.com
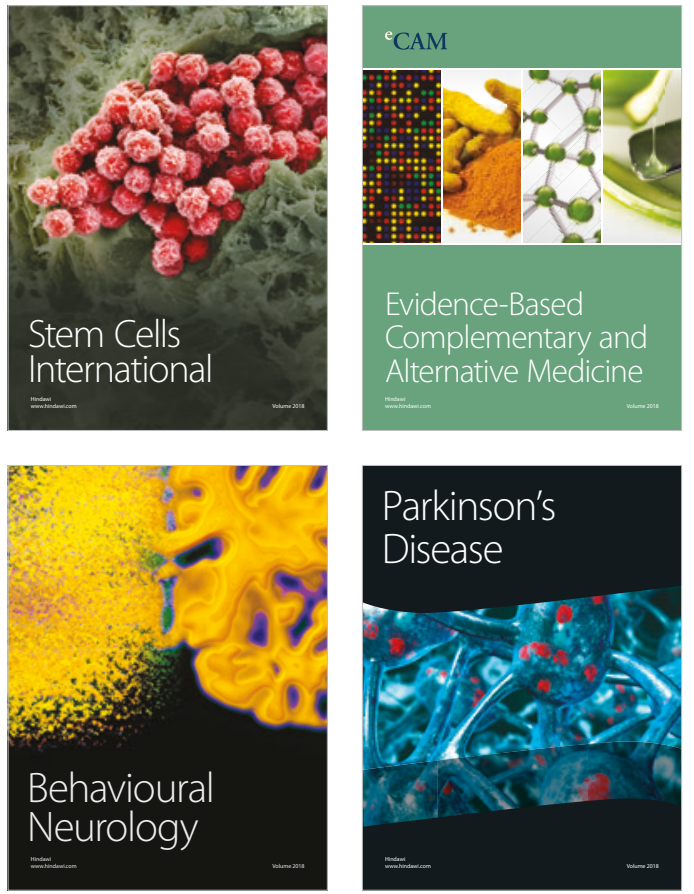

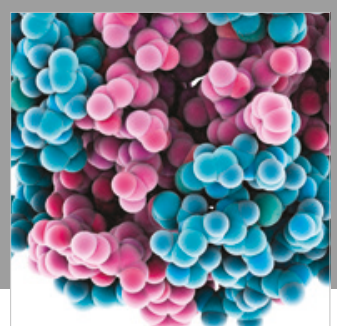

ournal of

Diabetes Research

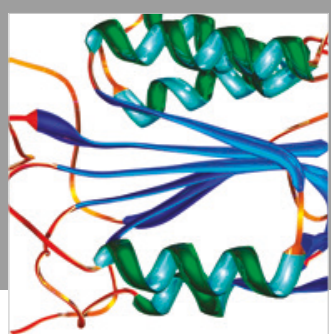

Disease Markers
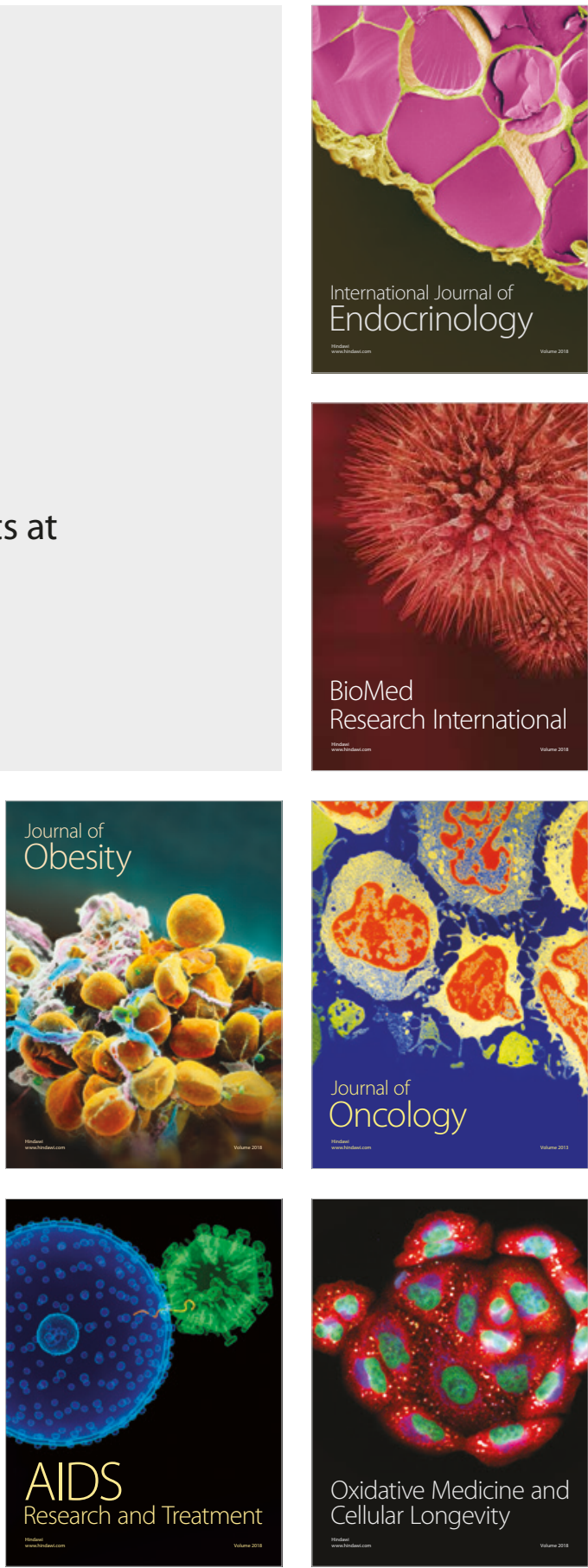